\title{
Leiomyosarcoma of Spermatic Cord: Mimicking Inguinal Hernia
}

\author{
Ali Koyuncuer \\ Department of Pathology, Hatay State Hospital, Hatay, Turkey.
}

\begin{abstract}
Leiomyosarcomas of the spermatic cord are very rare malignant neoplasms. We report one case, a 64-year-old man presented with the painless, swelling, ball shaped mass in the right inguinal canal.Histopathological evaluation including immunohistochemistrystudiesconfirmed a conventional leiomyosarcoma. Currently there has been no evidence local recurrence or distant metastasis for three months of follow-up. Leiomyosarcoma is a extremely malignant tumor; survival is poor. The long-termprognosis of leiomyosarcoma depends principally on stage and histologic grade. There appears to be a lack of concurrence aboutdiagnostic criteria for malignancy opposite the leiomyosarcoma spectrum, but more studies are needed.This article reviews in the literature and the criteria of these tumors is also discussed.
\end{abstract}

Keywords: Hernia, Inguinal, Leiomyosarcoma, Spermatic Cord

\section{Introduction}

Leiomyosarcomas prevalence ranging from approximately $5-10 \%$ of all soft tissue sarcomas [1].Paratesticular leiomyosarcomas which is usually located on the spermatic cord or epididymis [2]. Leiomyosarcoma of the spermatic cord is very rare and nowadays, 110 cases have been reported in the literature [3].A small number of cases of leiomyosarcoma appear to be primary spermatic cord, are more common uterin corpus and ganstointestinal system. There may be considerable problems with clinical and pathological the differential diagnosis, particularly malignant and benign smooth muscle cell tumor [4].The major differential diagnosis clinically is between inguinal hernia and inguinal ring (hernial) lipoma. In this case report, leiomyosarcoma of the spermatic cord soft tissue in a 64 year old man is described for its infrequency.

\section{Case Report}

A 64 year-old male arrived to the state hospital with compliant of a pain, constipation and burning/hot sensation around in the right groin. Clinical examination identified irreducible/strangulated righ inguinal hernia.Abdominal ultrasonography imaging revealed the presence of a solid mass in the right spermatic cord region, which was clinically considered as a may be tumor and was resected completely. Macroscopically, the tumor measured $5 \times 2 \times 3 \mathrm{~cm}$ in diameter. Gross findings nodular, grayish, firm, well-localized and well-demarcated and smooth mass. The cut surface of the tumor revealed ill-defined solid areas that were graywhite and brown, with focally hemorrhagic appearance and central degeneration (Figure 1). Macroscopically, tumor perforation and ulceration were not observed and the tumor margins were negative.Microscopically, the tumor appeared to consist predominantly interlacing bundles of smooth muscle cells with elongated and pink/ eosinophilic cytoplasm, centrally located nucleus and blunt-ended, cigar-shaped, frequently vesicular nuclei (Figure 2).Significant cytological pleomorphism was observed focally areas. Mitotic activity was showed; mitotic rate; 5-9 per 10 high-power fields (HPF)), in addition, focal necrosis were also present.Histologic Grade (French Federation of Cancer Centers Sarcoma Group [FNCLCC]): 2 (tumor differentiation is scored 2, mitosis countscored 1 and tumor necrosis scored 1). The tumor cells were positive for caldesmon, smooth muscle actin and desmin (Figure 3) but negative for S100, CD117 and CD34. The Ki67 (MIB-1, nuclear positivity) expression was approximately $40 \%$ positive in tumor cells, which showed a moderately proliferation index for the tumor. It was decided that all of these histopathological and immunohistochemically studies were diagnosis of conventional leiomyosarcoma (LMS).

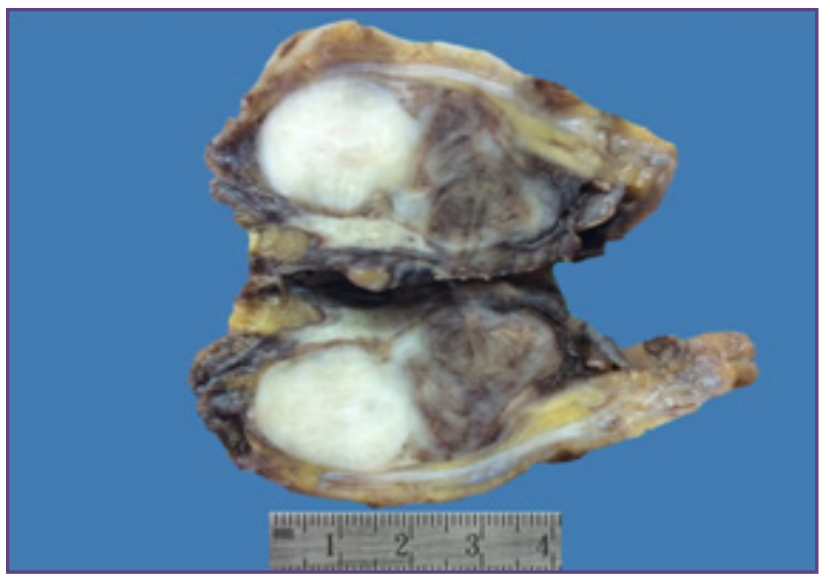

Fig. 1: Gross features: The macroscopic appearance nodular, well-localized and well-demarcated mass, ill-defined solid areas that were gray-white and brown, with focally hemorrhagic appearance and central degeneration. 


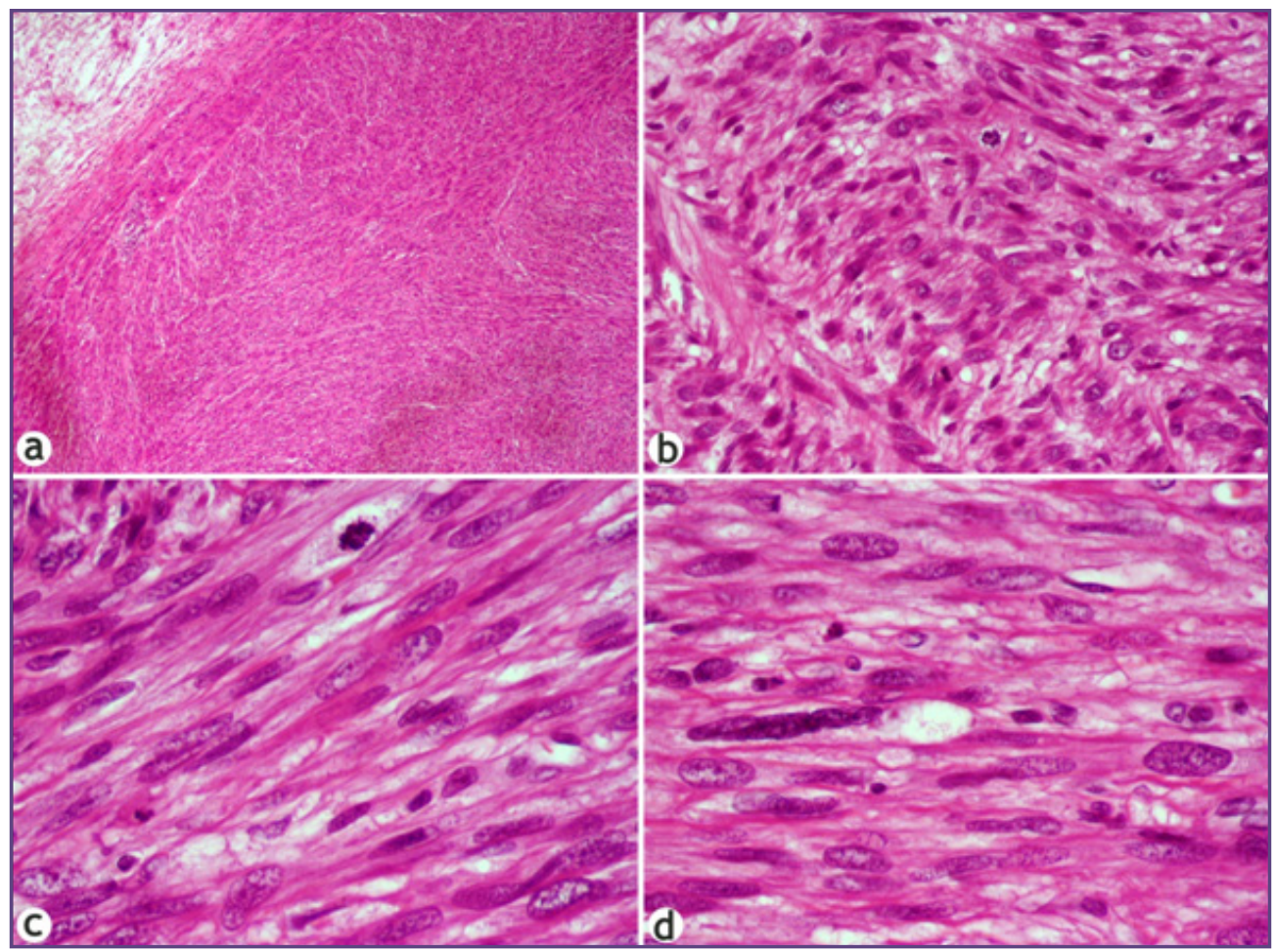

Fig. 2: Microscopically, A,B) The tumor appeared to consist predominantly interlacing bundles of smooth muscle cells with elongated and pink/eosinophilic cytoplasm, centrally located nucleus and blunt-ended, cigar-shaped, frequently vesicular nuclei. C,D) Significant cytological pleomorphismand mitotic activity was showed (H\&E, 4x, 10x, 20x objective).
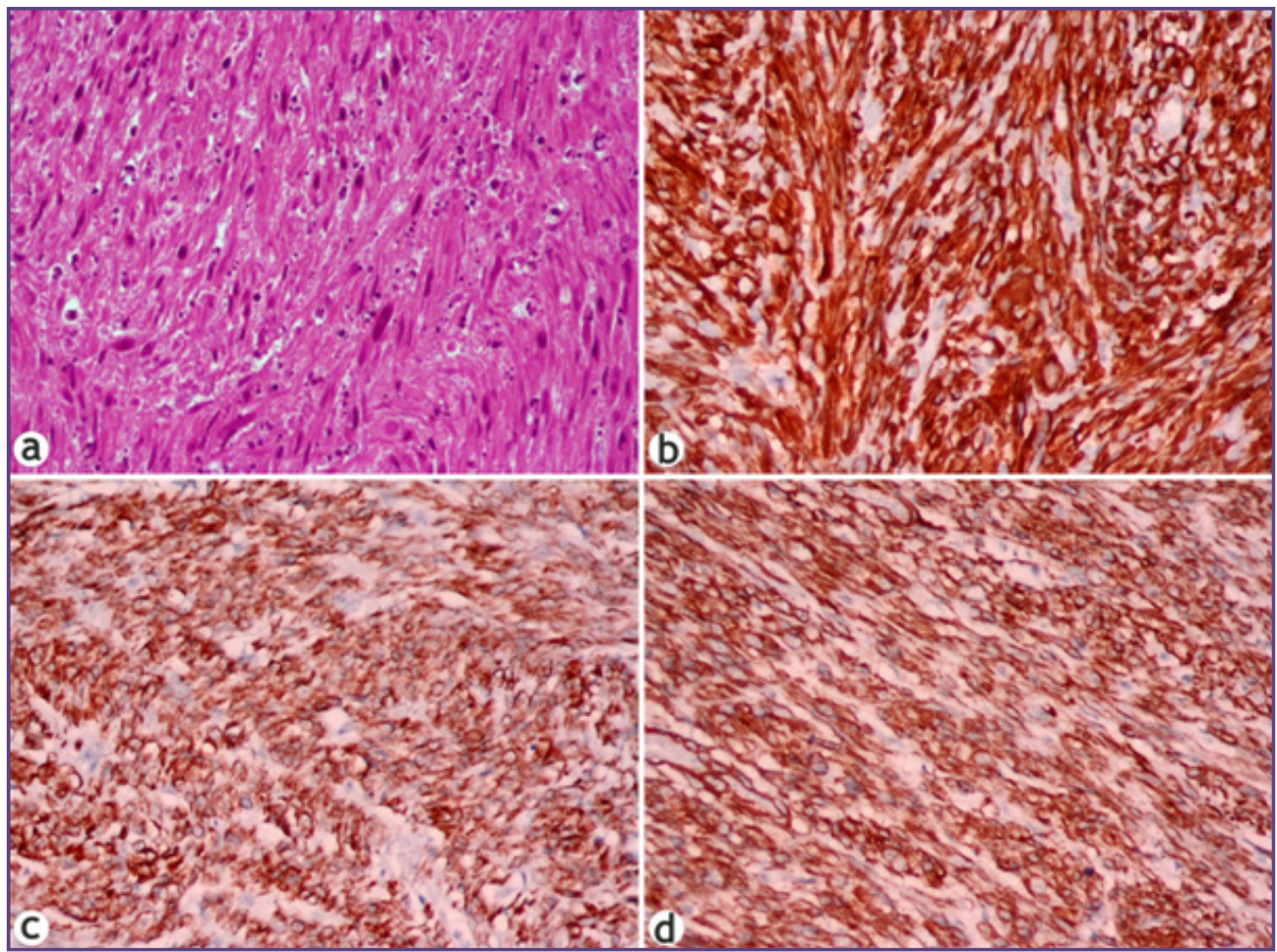

Fig. 3: A)Coagulative tumor necrosis (H\&E, 10x objective). Immunohistochemically positive for; B) Caldesmon; C) Desmin; D) Smooth Mucle Actin (SMA) (20x objective). 


\section{Discussion}

The paratesticular region is composed of the following anatomic structures: Rete testis, efferent ductules, epididymis, vas deferens (ductus deferens), testicular tunics and spermatic cord.Liposarcomas are the most prevalent malignant neoplasms of the paratesticular area ${ }^{[5]}$. Sarcoma of the spermatic cord first reported by Lesauvage in $1845^{[6]}$. LMS of the spermatic cord are uncommon neoplasia of non-testicular origin and generally arises in the sixth or seventh decade. Originally considered to be malignant smooth muscle tumors or leiomyosarcomas arise from embryologic undifferentiated mesenchymal cells of the cremasteric mucle or vas deferens cells ${ }^{[7]}$. Most paratesticular LMS are 2 to $9 \mathrm{~cm}$ in diameter ${ }^{[5]}$. LMS is subdivided into different groups on the basis of degreeand distribution of organ or tissue involvement; the three main subcategories are LMS of deep soft tissue, cutaneous/ subcutaneous tissue and vascular origin. Concordant with currentAmerican JointCommitee on Cancer Staging System, paratesticularsarcomas must be to the "deep" subgroup ${ }^{[8]}$.Smooth muscle tumours of the scrotum are are categorized into three major subtypes; leiomyoma, atypical leiomyoma and leiomyosarcoma ${ }^{[9,10]}$. The majority of these classifications believe mainly on histopathological four criteria to differentiate between subtypes, and were designed to be used; tumor size $\geq 5 \mathrm{~cm}$; infiltrating margin; $\geq 5$ mitotic figures 10 high-power field (HPF) and moderate cytological atypia [9]. Unfortunately, the morphologic features approved as predictive variables for uterine smooth muscle neoplasms were not, until recently, applied in extra-uterine smooth muscle tumors in the pelvic, retroperitoneum ${ }^{[11]}$. Because, it is not clear whether the few reported cases of LMSs of this paratesticular region. On the other hand, at least criteria for malignancy also is smooth muscle neoplasms contains different anatomic region and sex predicletion. In the retroperitoneum in female leiomyoma may exhibit mitotic activity (5-10/50 HPF) this presentation is probably considered leiomyoma ${ }^{[11]}$. However, Newman and Fletcher reported, the exhibit of along any mitotic activity was supported as a criterion of potential for malignancyin scrotal lesions ${ }^{[10]}$. Paratesticular leiomyosarcomas with mitotic activity, variable cellularity or atypia sometimes seen necrosis ${ }^{[5]}$. More recently reported any mitotic activity in a paratesticular region of smooth muscle neoplasia is an indicator to identify a LMS ${ }^{[5]}$. Similarly, Farshid et al reported mitotic activity seems to be significant in determination a malignant indication ${ }^{[12]}$. Most cases are usually positive for muscle-specific actin, smooth muscle actin, desmin ${ }^{[5]}, \mathrm{H}$-caldesmon and LMSs may also express cytokeratin, CD34, S-100, estrogen and progesterone receptors ${ }^{[1]}$. Caldesmon seems to be well specific stain for smooth muscle cells and extremely helpful in discrimination between smooth muscle neoplasia and other mesenchymal or stromal tumors ${ }^{[1]}$. The major prognostic factor predictive of metastasis and death is the histologic grade. Svarvar et al reported none of the grade 1 tumor metastasised while grade 2 and grade 3 tumors $\% 6.1$, $\% 25$ metastasised, respectively ${ }^{[13]}$. Quite often there is distant metastasis along hematogenous than the lymphatic line ${ }^{[4]}$. The most common location of the development of metastatic lesions is the lymph nodes, lungs, or liver ${ }^{[14]}$. Wecase underwent an without any complications postoperativecourse and after approximately three month of follow-up, there was no evidence of recurrent disease or metastasis.Local prophylactic radiotherapy planned postoperative. Considerations in the differential diagnosis of LMSs includes spindle cell neoplasms especially leiomyoma, and gastrointestinal stromal tumor, or other tumors; synovial sarcoma, malignant peripheral nerve sheath tumor, inflammatory myofibroblastic tumor, and pleomorphic sarcomas ${ }^{[1]}$. The standart treatment for spermatic cord LMSs radical orchidectomy and followed by adjuvant radiotherapy ${ }^{[15]}$.

\section{Conclusion}

Leiomyosarcomaof spermatic cord is an unusual neoplasm of soft tissue andshould be differential diagnosis forparticularly spindled cells tumors showing a predilection for the inguinal region.However, it should be kept in mind that these diagnostic criteria for malignancy across the leiomyoma spectrum, but more studies are needed. In addition to that close follow-up is extremely recommended for local recurrence or metastasis risk.

\section{Competing Interests}

The authors declare that there is no conflict of interests regarding the publication of this paper.

\section{References}

1. Goldblum JR, Folpe AL, Weiss SW. "Leiomyosarcoma". Enzinger and Weiss's Soft Tissue Tumors. 6th ed. Philadelphia, PA: Saunders; 2013, 549-68

2. Talikoti MA, Deo SS, Shukla NK, Kallianpur AA, Gupta M. "A rare case of giant leiomyosarcoma in a filarial scrotum: a case report". World J Surg Oncol, 201110; 9;20. doi: 10.1186/1477-7819-9-20.

3. Dangle P, Basavaraj DR, Bhattarai S, Paul AB, Biyani CS. "Leiomyosarcoma of the spermatic cord: case report and literature review".Can Urol Assoc J, 2007;1, 55-8, 2007

4. Kinjo M, Hokamura K, Tanaka K, Fujisawa Y, Hara S. "'Leiomyosarcoma of the spermatic cord. A case report and a brief review of literature". Acta Pathol Jpn, 1986;36,929-34

5. Amin MB, Grignon DJ, Srigley JR, Eble JN. 'Pathology of the Paratesticular Region" LippincottWilliams \&Wilkins, a Wolters Kluwer Philadelphia, PA ,pp. 804-54, 2014 
6. Frigerio P, Muruato-Araiza JS, Marcos-Morales S, CepedaNieto AC, Berdeal-Fernandez E, Zepeda-Contreras S. "Spermatic Cord Leiomyosarcoma Rare Case". Urol Case Rep, 2016; 23:15-7, 2016. doi: 10.1016/j.eucr.2016.01.002.

7. Dehghan A, Sami G, Eskandari N. "Leiomyosarcoma of the Spermatic Cord in a Seventy-Five-Year-Old man". Nephrourol Mon, 2015; 15, e24308. doi: 10.5812/ numonthly.24308. eCollection 2015.

8. Alberghini M, Zanella L, Bacchini P, Maltarello MC, Maraldi NM, Bertoni F. 'Leiomyosarcoma of the spermatic cord: a light and ultrastructural description of one case". Pathol Res Pract, 2004; 200:487-91.

9. Rana S, Sharma P, Singh P, Satarkar RN. "Leiomyoma of Scrotum: a Rare Case Report". Iran J Pathol, Summer, 2015;10:243-7.

10. Newman PL, Fletcher CD. "Smooth muscle tumours of the external genitalia: clinicopathological analysis of a series". Histopathology, 1991;18:523-9.
11. I. Mills, Stacey E., Greenson, Joel K., Hornick, Jason LLongacre, Teri A., V. Reuter, Victor E., Sternberg's Diagnostic Surgical Pathology. Sixth Edition Wolters Kluwer Health Philadelphia, PA, 2015

12. Farshid G, Pradhan M, Goldblum J, Weiss SW "Leiomyosarcoma of somatic soft tissues: a tumor of vascular origin with multivariate analysis of outcome in 42 cases". Am J Surg Pathol. 2002;26:14-24.

13. Svarvar C, Böhling T, Berlin O, et al. 'Scandinavian Sarcoma Group Leiomyosarcoma Working Group. Clinical course of nonvisceral soft tissue leiomyosarcoma in 225 patients from the Scandinavian Sarcoma Group". Cancer,2007;15:282-91.

14. Fisher C, Goldblum JR, Epstein JI, Montgomery E. "Leiomyosarcoma of the paratesticular region: a clinicopathologic study". Am J Surg Pathol, 2001;25:1143-9

15. Enoch S, Wharton SM, Murray DS. 'Management of leiomyosarcomas of the spermatic cord: the role of reconstructive surgery". World J Surg Oncol, 2005:28:23

*Corresponding author:

Dr. Ali Koyuncuer, Department of Pathology, Hatay State Hospital, Hatay, Turkey.

Phone: +91 905063819352, Fax: +9190326 2272440

Email: alikoyuncuer@hotmail.com

Date of Submission : 12.06.2017

Date of Acceptance : 22.09.2017

Financial or other Competing Interests: None.

Date of Publication : 11.10.2017 